Check for updates

Cite this: RSC Adv., 2018, 8, 34505

Received 1st August 2018

Accepted 23rd September 2018

DOI: $10.1039 / c 8 r a 06476 h$

rsc.li/rsc-advances

\section{Theophylline-bearing microspheres with dual features as a coordinative adsorbent and catalytic support for palladium ions $\dagger$}

\begin{abstract}
Katsuya Kaikake, iD * Masafumi Takada, Daiki Soma and Ren-Hua Jin (D) *
Polystyrenic microspheres in the sub 5 micrometer size range (micro-gel) with $-\mathrm{CH}_{2} \mathrm{Cl}$ active sites were synthesized via the dispersion polymerization of 4-chloromethylstyrene, divinyl benzene and methoxy polyethylene glycol acrylate. Then, theophylline residues were introduced onto the polystyrenic microspheres via the substitution of the chloride in the $-\mathrm{CH}_{2} \mathrm{Cl}$ group to prepare chelate type microspheres of $\mu$-T2. It was found that the microspheres have co-continuous structures, monodispersed particle sizes, and excellent solvent and water wettability. Using the $\mu$-T2 microspheres possessing theophylline residues, adsorption experiments involving the adsorption of palladium(॥), copper(II) and platinum(IV) from acidic chloride media under both individual and mixed conditions were carried out and it was found that the $\mu$-T2 microspheres exhibited excellent adsorption selectivity for palladium(॥) over copper(॥) and platinum(IV). It was also revealed that thiourea or ammonia solutions are the most effective in desorbing palladium ions from the microspheres. Despite being used in four adsorption-desorption cycles, the $\mu$-T2 microspheres were still able to strongly adsorb palladium ions, with an adsorption of over $85 \%$. In addition, the $\mu$-T2 microspheres also showed palladium capturing ability even in very dilute palladium solutions (below $1.0 \mathrm{ppm}$ ). Interestingly, the $\mu$-T2 microsphereadsorbed palladium ions exhibited excellent catalytic activity in the Suzuki-Miyaura coupling reaction of bromobenzene and phenylboronic acid, yielding biphenyl in 100\% under the conditions within 1 hour at $50{ }^{\circ} \mathrm{C}$ in water
\end{abstract}

\section{Introduction}

It is well known that palladium is a key element that is used in electronic devices, dental alloys, and as a catalyst in $\mathrm{C}-\mathrm{C}$ coupling and hydrogenation reactions, and is thus ranked as one of the most industrially indispensable elements. Demand for palladium has greatly increased in recent years, simultaneously accompanied by its high cost. ${ }^{1}$ However, the establishment of a recycling and reuse technique for palladium from waste containing palladium ions still remains a challenge. A practical and desirable solution to the recycling would be a highly-selective separation process employing heterogeneous adsorbents. There have been many reports on the recovery methods of palladium based on heterogeneous adsorbents ${ }^{2}$ that involve functional resins with chelate sites, ${ }^{3-6}$ grafted fibrous polymers $^{7,8}$ and natural polymers such as chitosan and tannin gels. ${ }^{\mathbf{9}, 10}$ In general, improvement of the adsorption ability was based on introducing chelate sites, such as high molecular

Department of Material and Life Chemistry, Faculty of Engineering, Kanagawa University, 3-27-1, Rokkakubashi, Kanagawa-ku, Yokohama, 221-8686, Japan. E-mail: kaikake@kanagawa-u.ac.jp; rhjin@kanagawa-u.ac.jp

$\dagger$ Electronic supplementary information (ESI) available. See DOI: 10.1039/c8ra06476h weight amines, aminobenzoic acid, phosphines, sulphides and thiourea onto the adsorbents. Recently, Nagai et al. reported an interesting recovery system for palladium by simply using melamine and cyanuric acid as capture sources, which can promote the in situ formation of supramolecular gels with palladium ions due to the formation of hydrogen bonds and electrostatic interactions between melamine, cyanuric acid and palladium. ${ }^{11,12}$ In this case, the soluble compounds melamine and cyanuric acid, when used as extraction sources, precipitate as insoluble gels once complexed with palladium ions, since the palladium ions just act as a cross-linker. In an early report, it was shown that xanthine derivatives, such as theophylline and theobromine, are effective ligands for selectively capturing palladium ions and using them in a liquid-liquid extraction process for the selective recovery of palladium in mixed metal ions. $^{\mathbf{1 3 , 1 4}}$ Unfortunately, this is not an attractive recycling approach because the theophylline-palladium complex is very soluble and thus consumes a lot of organic solvents in the extraction process. An effective method for solving this problem is to fix theophylline residues onto a solid surface that has hydrophilic features. In general, polystyrenic-type resins consisting of chloromethylstyrene moieties are commercially available ${ }^{15}$ but they are made up of large particles and are hydrophobic materials, rendering them unsuitable for use as 
high quality adsorbents. There have been many reports on the preparation of polystyrenic monodispersed microspheres of 1-3 $\mu \mathrm{m}$ in size that possess a high content of $-\mathrm{CH}_{2} \mathrm{Cl}$ functional groups, ${ }^{\mathbf{1 6}}$ which can be conveniently transformed to target functional groups via simple chemical modifications. ${ }^{17}$ Very recently, we reported the preparation of sub-5 $\mu \mathrm{m}$ silica microspheres with co-continuous structures using cross-linked poly(chloromethylstyrene) microspheres ( $\mu-1)$ as starting materials via polymerization and silicification reactions on the microspheres. ${ }^{18}$ In this case, $\mu-1$ microspheres were used as initiators for the polymerization of oxazoline and the grafted polyoxazoline chains were transformed into polyethyleneimine, which was finally used as a catalytic template to deposit silica on the microspheres. In particular, we found that the formation of silica on the swollen-state microspheres easily afforded a cocontinuous structure through the inside of the sub-5 $\mu \mathrm{m}$ diameter. This led us to believe that the $\mu-1$ microspheres obtained via our preparation scheme are ready to produce cocontinuous structures and thus prompted us to introduce theophylline residues into the co-continuous microspheres for the preparation of a material with dual adsorbent and catalytic support features for palladium ions. When we were setting out to do our experiments, Guterman et al. reported the synthesis of theophylline-containing microspheres. They prepared a monomer of theophylline-substituted styrene obtained from the reaction between theophylline and chloromethylstyrene, and polymerized the monomer via a dispersion-polymerization method. ${ }^{19}$ However, their microspheres bearing theophylline were synthesized without cross-linkers and no use of the microspheres was mentioned.

Herein, we synthesized monodispersed sub-5 $\mu \mathrm{m}$ microspheres with $-\mathrm{CH}_{2} \mathrm{Cl}$ reactive sites via the dispersionpolymerization of chloromethylstyrene, PEGylated acrylate, and divinylbenzene and then transformed the microspheres into theophylline-bearing $\mu$-T2 microspheres. The $\mu$-T2 microspheres were characterized by Fourier-transform infrared FT-IR spectroscopy, scanning electron microscopy (SEM), dynamic light scattering (DLS), solid state ${ }^{13} \mathrm{C}$ nuclear magnetic resonance (NMR) and the successful synthesis of the co-continuous structures was confirmed from the SEM images of the sectioned microspheres. Employing the $\mu-\mathrm{T} 2$ microspheres with cocontinuous structures as a coordinative adsorbent and catalyst support for palladium ions, we were able to recover palladium ions and use them in the catalysis of the Suzuki-Miyaura coupling reaction and found that the $\mu$-T2 microspheres are not only an excellent adsorbent, but also an effective catalyst support for palladium ions.

\section{Experimental}

\section{Materials}

4-Chloromethylstyrene (CMS, >90\%, TCI) was purified by column chromatography with basic aluminum oxide (Aldrich) to remove the stabilizer before use. Divinylbenzene (DVB, $m$ and $p$-mixture, $>50 \%$, TCI) was extracted from a sodium hydroxide aqueous solution ( $1 \mathrm{M}$ ) to remove the polymerization inhibitor before use. 2,2'-Azobis(isobutyronitrile) (AIBN, >98\%,
TCI) was crystallized from ethanol. Methoxy polyethylene glycol acrylate AM-90G (MGA, - $\left.\left(\mathrm{OCH}_{2}-\mathrm{CH}_{2}\right)_{9}\right)$ was provided by ShinNakamura Chemical Co., Ltd. Potassium carbonate $\left(\mathrm{K}_{2} \mathrm{CO}_{3}\right.$, $>99.0 \%$, TCI), dimethylacetamide (DMAc, Super dehydrated, $>99.5 \%$, Wako), polyvinylpyrrolidone K25 (PVP, Wako), hydrochloric acid (5 M, Wako), ethanol ( $>99.5 \%$, Wako), theophylline (Wako), palladium chloride (>99.0\%, Wako), hydrogen hexachloroplatinate(Iv) hexahydrate $\left(\mathrm{H}_{2} \mathrm{PtCl}_{6} \cdot 6 \mathrm{H}_{2} \mathrm{O},>98.5 \%\right.$, Wako), copper(II) chloride dihydrate $\left(\mathrm{CuCl}_{2} \cdot 2 \mathrm{H}_{2} \mathrm{O},>99.0 \%\right.$, Wako), bromobenzene $(>99.0 \%, \mathrm{TCI})$, phenylboronic acid (TCI), chloroform-D1 $\left(\mathrm{CDCl}_{3}>99.8 \%, 0.03 \% \mathrm{TMS}\right)$ and other reagents were used as received without further purification.

\section{Synthesis of the poly(p-chloromethylstyrene) microspheres $(\mu-1)$}

Polystyrenic microspheres $(\mu-1)$ were synthesized via a dispersion polymerization process ${ }^{\mathbf{2 0 - 2 2}}$ according to our previous method, ${ }^{18}$ as shown in Scheme 1 . To a $300 \mathrm{~mL}$ three necked round-bottomed flask equipped with a condenser, ethanol (solvent, $150 \mathrm{~mL}$ ), DMAc (co-solvent, $18 \mathrm{~mL}$ ), and polyvinylpyrrolidone (PVP K25, $1.8 \mathrm{~g}$ ) were added, and the mixture was stirred at room temperature (r.t.) until PVP was completely dissolved. Then, divinylbenzene (DVB) $(95 \mu \mathrm{L}, 0.67 \mathrm{mmol}(2.0 \%$ cross-linking degree)) and CMS (4.6 mL, $33.1 \mathrm{mmol}$ ) were added, and then nitrogen was bubbled through the solution for $30 \mathrm{~min}$ to purge the dissolved oxygen. After heating the solution to $60{ }^{\circ} \mathrm{C}$, AIBN (initiator, $0.107 \mathrm{~g}, 0.67 \mathrm{mmol}$ ) dissolved in $5 \mathrm{~mL}$ of ethanol was added and then the mixture was stirred at the same temperature for $24 \mathrm{~h}$. After polymerization, the obtained suspension products were collected by centrifugation (4000 rpm, $5 \mathrm{~min}$ ), washed with methanol to remove PVP and non-reacted monomers, and then dried under reduced pressure at $50{ }^{\circ} \mathrm{C}$ for $6 \mathrm{~h}$. White powders of $\mu$-1 were obtained in $28 \%$ yield, weighing $1.5 \mathrm{~g}$.

\section{Synthesis of the polystyrenic microspheres containing theophylline ( $\mu$-T1)}

The introduction of theophylline to the polychloromethylstyrene segment was performed as follows. $0.7 \mathrm{~g}$ of $\mu-1$ microspheres $\left(-\mathrm{CH}_{2} \mathrm{Cl}\right.$ unit: $\left.4.2 \mathrm{mmol}\right)$ were added into DMAc $(50 \mathrm{~mL})$ in a two necked round-bottomed flask and sonicated for a short period of time (3-5 min). Then, theophylline $(1.5 \mathrm{~g}, 8.3 \mathrm{mmol})$ and potassium carbonate $(0.7 \mathrm{~g}, 5.1$ mmol) were added. This mixture was stirred at $80{ }^{\circ} \mathrm{C}$ for $72 \mathrm{~h}$. After cooling, the suspension products were collected by centrifugation (4000 rpm, $5 \mathrm{~min}$ ), washed with distilled water to remove the excess amounts of theophylline and DMAc, and then dried under reduced pressure at r.t. for $12 \mathrm{~h}$. The $\mu-\mathrm{T} 1$ microspheres were obtained as a white powder weighing $1.1 \mathrm{~g}$.

\section{Synthesis of the poly ( $p$-chloromethylstyrene-ran- methoxypolyethylene glycol acrylate) microspheres ( $\mu-2)$}

In order to improve the affinity of the $\mu-1$ microspheres to an aqueous phase, microspheres with poly(ethylene)glycol (PEG) chains were synthesized via the copolymerization of CMS, MGA and DVB. Typically, to a $300 \mathrm{~mL}$ three necked round-bottomed flask equipped with a condenser, ethanol (solvent, $150 \mathrm{~mL}$ ), 
<smiles>C=Cc1ccc(CCl)cc1</smiles>

CMS
$+$<smiles>C=Cc1ccc(C=C)cc1</smiles>

DVB (2 mol\%)

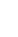<smiles>C=Cc1ccc(C=C)cc1</smiles>

CMS
MEGA
DVB (2 $\mathrm{mol} \%)$

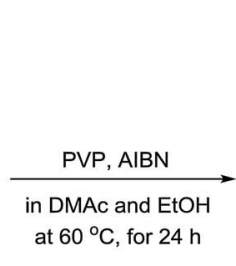

$\underset{\text { in DMAC and EtOH }}{\stackrel{\text { MEGA , PVP, AIBN }}{\longrightarrow}}$

at $60^{\circ} \mathrm{C}$, for $24 \mathrm{~h}$
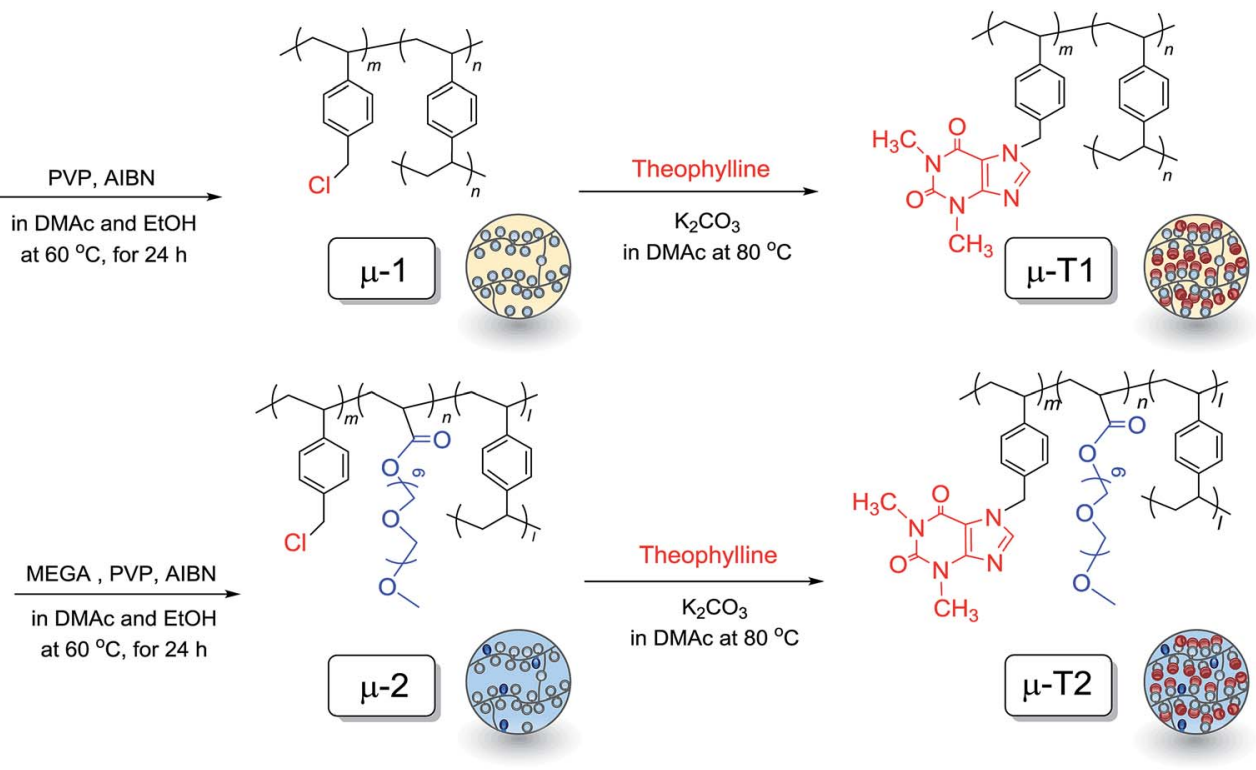

Scheme 1 Synthetic procedures for the formation of the two types of theophylline-containing microspheres.

DMAc (co-solvent, $18 \mathrm{~mL}$ ), and polyvinylpyrrolidone (PVP K25, $1.8 \mathrm{~g})$ were added, and the mixture was stirred at room temperature until PVP was completely dissolved. Then, DVB (95 $\mu \mathrm{L}, 0.67 \mathrm{mmol}(2.0 \%$ cross-linking degree $))$ and CMS $(4.6 \mathrm{~mL}$, $33.1 \mathrm{mmol}$ ) were added, and then nitrogen was bubbled through the solution for $30 \mathrm{~min}$ at $60{ }^{\circ} \mathrm{C}$. Finally, AIBN (initiator, $0.107 \mathrm{~g}, 0.67 \mathrm{mmol}$ ) dissolved in $5 \mathrm{~mL}$ of ethanol was added, and then the mixture was stirred at the same temperature for $24 \mathrm{~h}$. After cooling, the suspension products were collected by centrifugation (4000 rpm, $5 \mathrm{~min}$ ), washed with methanol to remove PVP and unreacted monomers, and then dried under reduced pressure at r.t. for $12 \mathrm{~h}$. The $\mu-2$ microspheres were obtained as a white powder weighing $0.8 \mathrm{~g}$.

\section{Synthesis of the poly( $p$-chloromethylstyrene-ran-} methoxypolyethylene glycol acrylate) microspheres bearing theophylline $(\mu-\mathrm{T} 2)$

$0.5 \mathrm{~g}$ of $\mu-2$ microspheres $\left(-\mathrm{CH}_{2} \mathrm{Cl}\right.$ unit: $\left.2.7 \mathrm{mmol}\right)$ were added into DMAc $(35 \mathrm{~mL})$ and sonicated for several minutes. After heating to $80{ }^{\circ} \mathrm{C}$, theophylline $(1.0 \mathrm{~g}, 5.5 \mathrm{mmol})$ and potassium carbonate ( $0.6 \mathrm{~g}, 4.3 \mathrm{mmol})$ were added, and the mixture was stirred at the same temperature for $72 \mathrm{~h}$. After cooling, the suspension products were collected by centrifugation (4000 rpm, $5 \mathrm{~min}$ ), washed three times with methanol to remove the excess amounts of theophylline and DMAc, and then dried under reduced pressure at room temperature for $12 \mathrm{~h}$. Yield: $0.5 \mathrm{~g}$ as a white powder.

\section{Adsorption of the metal ions}

All experiments concerning the adsorption equilibria were performed using a batch-wise shaking method in a bioshaker at $30{ }^{\circ} \mathrm{C}$. An aqueous solution was prepared by dissolving a known amount of metal chloride in a $1.0 \mathrm{mmol} \mathrm{dm}{ }^{-3}$ hydrochloric acid solution. After adsorption, the microspheres were removed via filtration and the metal ion content in the filtrate was measured by inductively coupled plasma spectrophotometry. The amount of metal ions adsorbed in the microspheres was calculated from the difference between the initial concentration $\left(C_{\mathrm{Maq}}\right)$ in the aqueous phase and the adsorption equilibrium concentration $\left(C_{\text {Meq }}\right)$ in the aqueous phase. Here, the adsorption percentage of the metal ions is defined by eqn (1)

$$
\text { adsorption rate }=\left(\frac{C_{\mathrm{Maq}}-C_{\mathrm{Meq}}}{C_{\mathrm{Maq}}}\right) \times 100(\%) .
$$

\section{Catalysis of the Pd-loaded microspheres in the Suzuki- Miyaura coupling reaction}

Pd-loaded $\mu$-T2 microspheres were used as a solid-type catalyst for the following reaction. To a $6 \mathrm{~mL}$ screw top tube, bromobenzene $(0.08 \mathrm{~g}, 0.5 \mathrm{mmol})$, phenylboronic acid $(0.09 \mathrm{~g}, 0.75$ $\mathrm{mmol}), \mathrm{K}_{2} \mathrm{CO}_{3}(0.35 \mathrm{~g}, 2.5 \mathrm{mmol})$, the palladium-adsorbed microspheres (0.02-2.0 mol\% Pd catalyst) and distilled water $(2.0 \mathrm{~mL})$ were added in order, and then the mixture was stirred at $20-80{ }^{\circ} \mathrm{C}$ in air for different periods of time. After that, the mixed solution was extracted with $\mathrm{CDCl}_{3}(3 \mathrm{~mL})$, and then the $\mathrm{CDCl}_{3}$ layer was washed with distilled water $(7 \mathrm{~mL})$ and dried over a small amount of $\mathrm{Na}_{2} \mathrm{SO}_{4}$. The $\mathrm{CDCl}_{3}$ solution was measured by ${ }^{1} \mathrm{H}-\mathrm{NMR}$ to estimate the conversion and synthesis of the biphenyl product. The catalytic recyclability of the Pdloaded microspheres was tested 4 times under conditions of $2 \mathrm{~mol} \%$ catalyst at $50^{\circ} \mathrm{C}$ for $1 \mathrm{~h}$ via the collection of the catalyst powders by filtration (membrane filter, JG $0.20 \mu \mathrm{m}$ ).

\section{Characterization}

The FT-IR spectra were recorded on a Jasco FT/IR-4600 spectrometer by diffusing the samples in $\mathrm{KBr}$ pellets. ${ }^{13} \mathrm{C}$ cross polarization magic angle spinning (CP/MAS) NMR spectra were obtained using a JEOL ECA-400 spectrometer operated at 100.53 $\mathrm{MHz}$. The amount of theophylline residues in the microspheres 
was estimated from the nitrogen content of the elemental analysis, recorded on a PERKIN ELMER Series II CHNS/O Analyzer 2400 II. SEM observations were performed using a HITACHI SU-8010 microscope at $1.5 \mathrm{kV}$ after the samples were sputtered with Pt particles. The particle size distribution of the microspheres was measured by dynamic light scattering (DLS) (Otsuka Electronics Co. Ltd., Fiber Optics Particle Analyzer FPAR-1000) in methanol under sonication. $\mathrm{N}_{2}$ adsorption/ desorption isotherms were obtained using a Micrometrics Tristar-3000 instrument at liquid-nitrogen temperature, whereby all samples were degassed at $120{ }^{\circ} \mathrm{C}$ under a vacuum for $3 \mathrm{~h}$ prior to analysis. All experiments concerning the adsorption equilibria were performed using a batch-wise method at $30{ }^{\circ} \mathrm{C}$ in a bio-shaker (TAITEC Co., Ltd, Bio Shaker $\mathrm{BR}-23 \mathrm{FH}$ ). The metal ion content in the aqueous solutions was measured by inductively coupled plasma spectrophotometry (SHIMADZU, ICPE-9820) and inductively coupled plasma mass spectrometry (ICP-MS) (Agilent, 7700X ICP-MS).

\section{Results and discussion}

\section{Synthesis and characterization of the $\mu-1, \mu-\mathrm{T} 1, \mu-2$ and $\mu$-T2 microspheres}

As shown in Scheme 1, two types of polystyrenic microspheres were synthesized. One is the $\mu-1$ microspheres copolymerized from chloromethylstyrene and divinylbenzene and the other is the $\mu-2$ microspheres copolymerized from chloromethylstyrene, methoxypolyethylene glycol acrylate (MGA) and divinylbenzene. The former has totally hydrophobic components, while the latter has a partial hydrophilic component, MGA. Subsequent reactions of the two types of spheres with theophylline resulted in the formation of the corresponding $\mu-\mathrm{T} 1$ and $\mu$-T2 microspheres.

Fig. 1 and 2 show the FT-IR and ${ }^{13} \mathrm{C}-\mathrm{NMR}$ spectra of the $\mu-1$, $\mu-\mathrm{T} 1, \mu-2$, and $\mu-\mathrm{T} 2$ microspheres. From the comparison of the FT-IR spectra of the four samples, it is clear that the characteristic vibration peaks at $670\left(\mathrm{C}-\mathrm{Cl}\right.$ stretching) and $1260 \mathrm{~cm}^{-1}$ (C-Cl bending) due to the $-\mathrm{CH}_{2} \mathrm{Cl}$ groups in both $\mu-1$ and $\mu-2$ were not present in the spectra of both $\mu$-T1 and $\mu$-T2 containing the theophylline moieties. Alternatively, new stretching vibration peaks appeared in the spectra of the $\mu$-T1 and $\mu-\mathrm{T} 2$ microspheres at 1701 and $1665 \mathrm{~cm}^{-1}$, and 1703 and $1654 \mathrm{~cm}^{-1}$, due to the presence of two $\mathrm{C}=\mathrm{O}$ groups on the rings of the theophylline residues. In the ${ }^{13} \mathrm{C}-\mathrm{CP} / \mathrm{MAS}$ NMR spectra shown in Fig. 2, a chemical shift at $50 \mathrm{ppm}$ due to the $-\mathrm{CH}_{2} \mathrm{Cl}$ group was observed for the two types of microspheres before the introduction of theophylline. Compared to the spectrum of the $\mu-1$ microspheres, the PEG-containing $\mu-2$ microspheres showed a chemical shift at around $70 \mathrm{ppm}$, which was assigned to the presence of ethylene glycol units $\left(\mathrm{OCH}_{2} \mathrm{CH}_{2}\right)$. After theophylline introduction, the spectra of both the $\mu-1$ and $\mu-2$ microspheres showed new chemical shifts at 155, 149, 146 and 105 ppm assigned to the carbons on the xanthine ring, and at $29 \mathrm{ppm}$ due to the presence of $\mathrm{N}-\mathrm{CH}_{3}$ groups. These results strongly support the efficient introduction of theophylline into both types of microspheres. The amounts of theophylline moieties on the microspheres were estimated to be 2.8 (for $\mu-\mathrm{T} 1$ ) and $2.6 \mathrm{mmol} \mathrm{g}^{-1}$ (for $\mu$-T2), respectively, on the basis of the

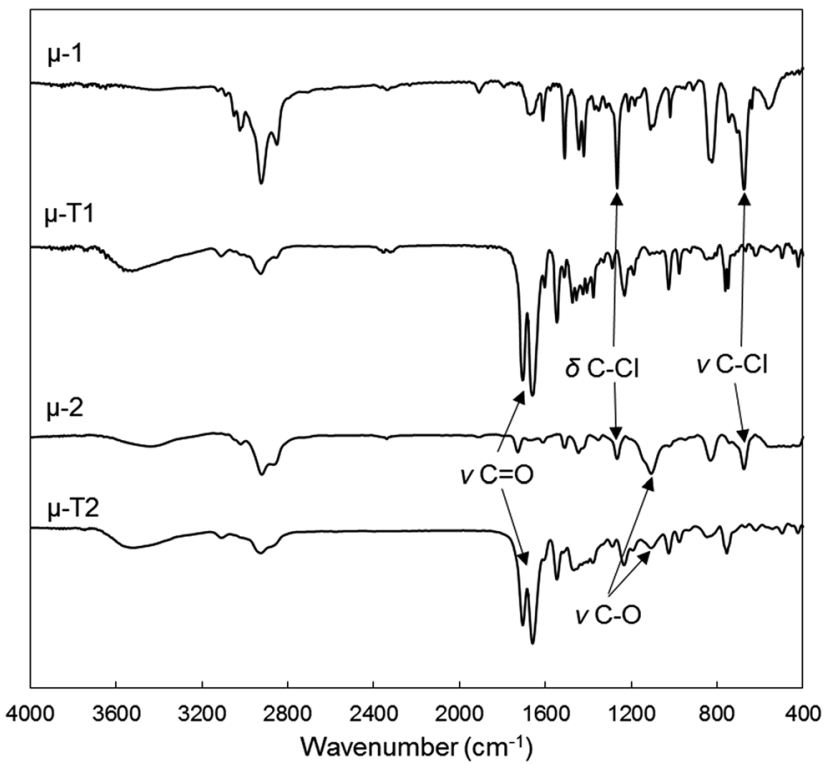

Fig. 1 FT-IR spectra of the polystyrene-type microspheres $(\mu-1, \mu-T 1)$ and MGA copolymer-type microspheres $(\mu-2, \mu-T 2)$.

nitrogen content measured by elemental analysis. These results indicate that the transformation of chloromethylstyrene-type microspheres into theophylline-bearing microspheres is very easy.

To confirm the hydrophilicity of the $\mu-\mathrm{T} 1$ and $\mu$-T2 microspheres, we compared their wettability by putting the two samples into a phase-separated mixture of diethyl ether/water. As seen from the image shown in Fig. S1, $\dagger$ the $\mu$-T1 microspheres dispersed into the upper ether phase when they were put into the mixture. In contrast, in the case of $\mu$-T2, the microspheres were well dispersed in the lower water phase. This simple comparison directly showed that the $\mu$-T2 PEGcontaining microspheres are sufficiently hydrophilic and are suitable to be used in aqueous conditions.

In order to evaluate the morphological structures of the microspheres, the four kinds of microspheres were subjected to SEM. As shown in Fig. 3, the $\mu-1$ and $\mu$-T1 powders contain 1-2 $\mu \mathrm{m}$ sized spheres, with smooth surfaces. In comparison, the surface of the spherical $\mu-2$ and $\mu-\mathrm{T} 2$ particles have bumpy structures with a lot of nanopores and the diameters of the spheres are larger than the former microspheres. Interestingly, the sectioned image of $\mu$-T2 exhibits a co-continuous structure where the nanoparticles are joined to one another to make a dense fibrous network with empty space inside (Fig. S2 $\dagger$ ). However, there are no differences in the specific surface area for the four microspheres, as measured by $\mathrm{N}_{2}$ adsorption (see Table $\mathrm{S} 1 \dagger$ ). The calculated Brunauer-Emmett-Teller (BET) surface areas of the microspheres were in the range of $1.5-1.9 \mathrm{~m}^{2} \mathrm{~g}^{-1}$.

We further measured the differences between the microsphere pairs $\mu-1$ and $\mu-\mathrm{T}$, and $\mu-2$ and $\mu-\mathrm{T} 2$, by conducting DLS measurements in $\mathrm{MeOH}$. As shown in Fig. S3, $\uparrow$ the average diameter of the spheres after the introduction of the theophylline residues increased by about $200 \mathrm{~nm}$ than that of the precursors indicating that the theophylline residues in the spheres effectively increased the swelling ability of the spheres in methanol. 

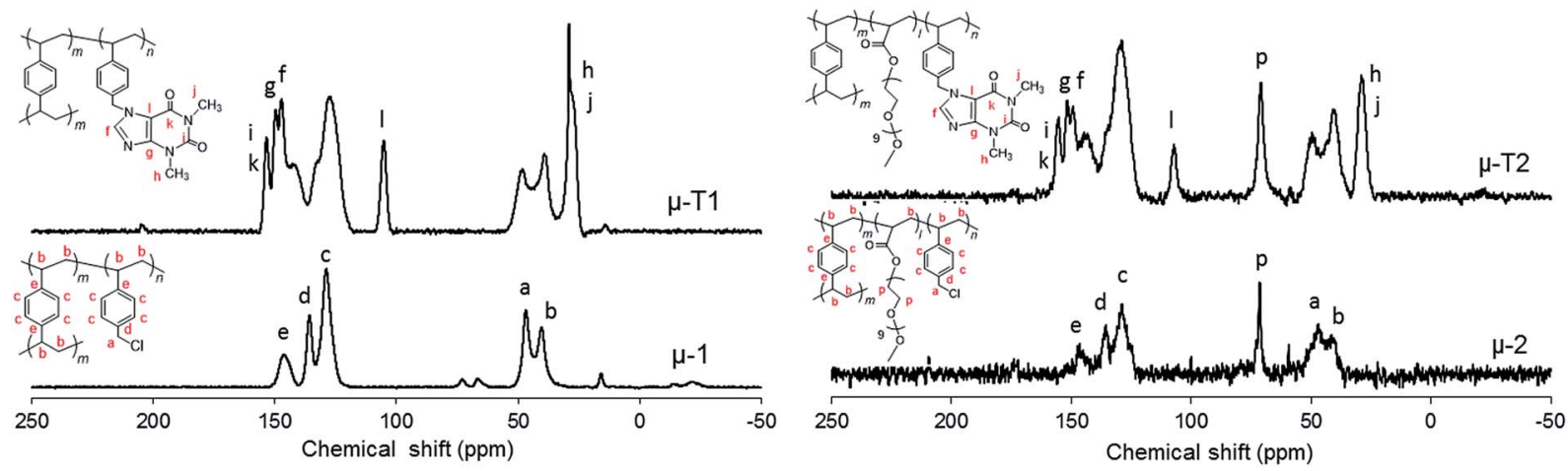

Fig. 2 Comparison of the ${ }^{13} \mathrm{C}$ CP/MAS NMR (100.53 MHz) spectra of the polystyrene-type microspheres and MGA copolymer type microspheres.
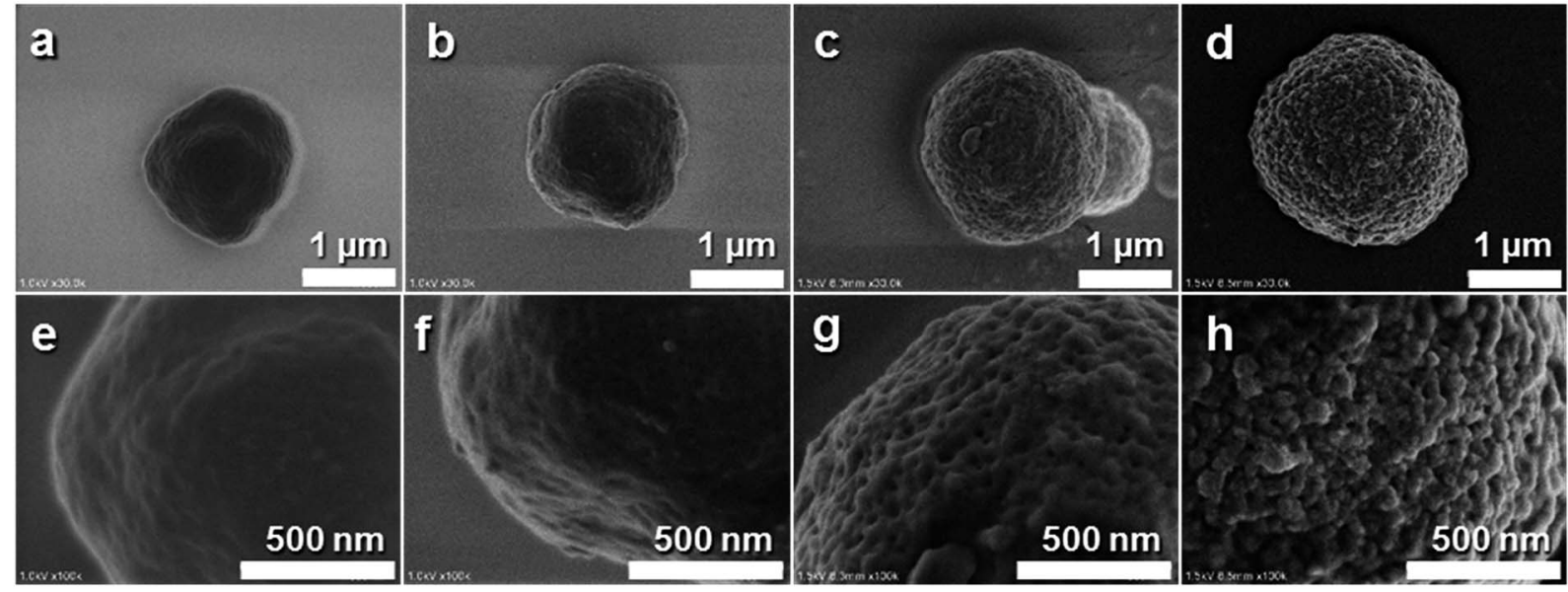

Fig. 3 SEM images of the four types of microspheres (a and e) $\mu-1$, (b and f) $\mu-T 1$, (c and g) $\mu-2$, (d and h) $\mu-T 2$.

Also, the spheres possessing PEG components has larger diameters $(1278 \mathrm{~nm}$ for $\mu-2$ and $1551 \mathrm{~nm}$ for $\mu$-T2) than those $(1112 \mathrm{~nm}$ for $\mu-1$ and $1321 \mathrm{~nm}$ for $\mu$-T1) without PEG. Upon using the $\mu$-T2 spheres to adsorb Pd(II) ions, the diameter decreased to $1398 \mathrm{~nm}$ from $1551 \mathrm{~nm}$ suggesting the cross-linking role ${ }^{23}$ of the $\mathrm{Pd}(\mathrm{II})$ ions between theophylline residues due to the strong coordinative interactions of Pd and theophylline.

\section{Adsorption of palladium on the theophylline-bearing microspheres}

Based on the above characterization, it was expected that the $\mu$-T2 microspheres, with their co-continuous structure, waterwettability and good swelling properties, would be desirable to use for the adsorption of Pd ions from aqueous media. We performed a series of experiments involving the adsorption of palladium ions using the $\mu$-T2 microspheres, while the $\mu$-T1 sample was also used for comparison. Fig. 4 shows the relationship between the adsorption time and adsorption rate of the palladium ions. It is remarkable that the adsorption of the $\mu$-T2 system reached nearly $96 \%$ in $4 \mathrm{~h}$. In contrast, in the case of the $\mu$-T1 sample, the adsorption rate reached $86 \%$, after a very long time $(72 \mathrm{~h})$. Such a distinguished feature of the $\mu$-T2 microspheres should be attributed to their co-continuous structure and water-wettability properties, which enhancement the diffusion of Pd ions into the spheres.

In order to examine the separation of palladium(II) from a mixture containing other metal ions, the selective adsorption of palladium(II) from a mixed solution containing platinum(Iv) or copper(II) was investigated. As shown in Fig. 5, interestingly,

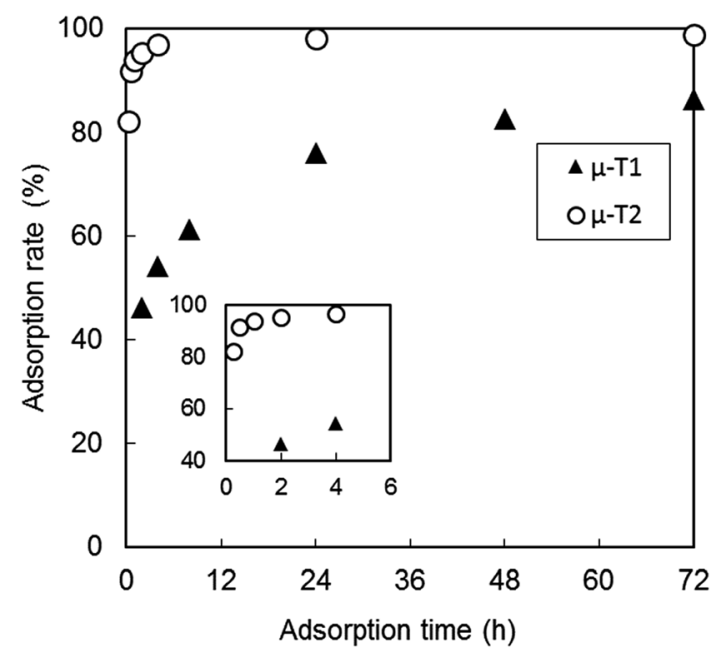

Fig. 4 Ability of the $\mu-\mathrm{T} 1$ and $\mu-\mathrm{T} 2$ microspheres to adsorb palladium. 


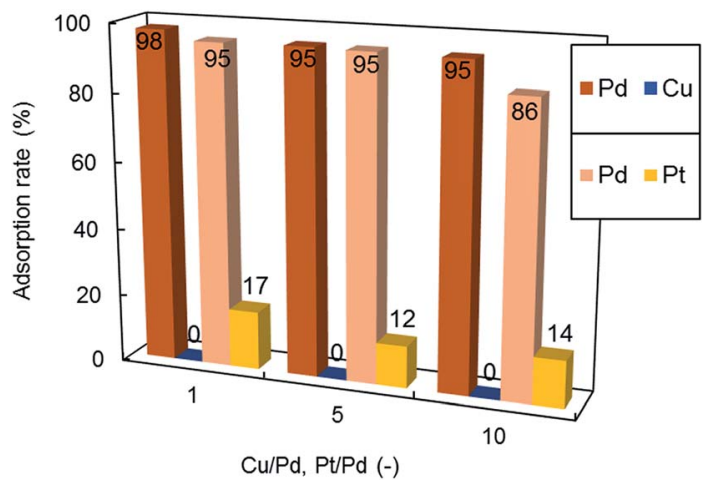

Fig. 5 Selective adsorption of $\mathrm{Pd}(॥)$ by $\mu-\mathrm{T} 2$ in the mixed solution containing $\mathrm{Cu}(\mathrm{II})$ or Pt(IV).

palladium(II) was selectively adsorbed onto the $\mu$-T2 microspheres from a mixed solution containing 10 times the amount of platinum(Iv) or copper(II) than palladium. This indicates that the $\mu$-T2 microspheres have high selectivity for the adsorption of palladium(II) ions despite the co-existence of a higher content of other metal ions.

From the viewpoint of recycling, the desorption of Pd(II) from the adsorbent is important in order to recover palladium(II) from liquid waste. Therefore, we further performed desorption and re-adsorption experiments using $\mu$-T2 microspheres that had been fully adsorbed with palladium ions in advance. In the desorption experiments, shown in Fig. 6, two different aqueous solutions, $1.0 \mathrm{~mol} \mathrm{dm}^{-3}$ ammonia and/or $1.0 \mathrm{~mol} \mathrm{dm}^{-3}$ thiourea, were used, and it was found that these solutions were sufficient to desorb the $\mathrm{Pd}(\mathrm{II})$ ions from the microspheres. In the first re-adsorption experiments, the recovery of $\mathrm{Pd}(\mathrm{II})$ reached $95 \%$ and $96 \%$, respectively, reusing the $\mu$-T2 sample after being desorbed by ammonia and thiourea. When such a cycle was repeated four times, the recovery of the $\operatorname{Pd}(\mathrm{II})$ ions was decreased somewhat to $85 \%$ (ammonia) and 90\% (thiourea). These results suggest that the thiourea solution is more suitable to use as a desorption chemical for the recovery of palladium. Moreover, the $\mu$-T2 microspheres seemed to be durable in strong acid media during the repeated adsorption process.

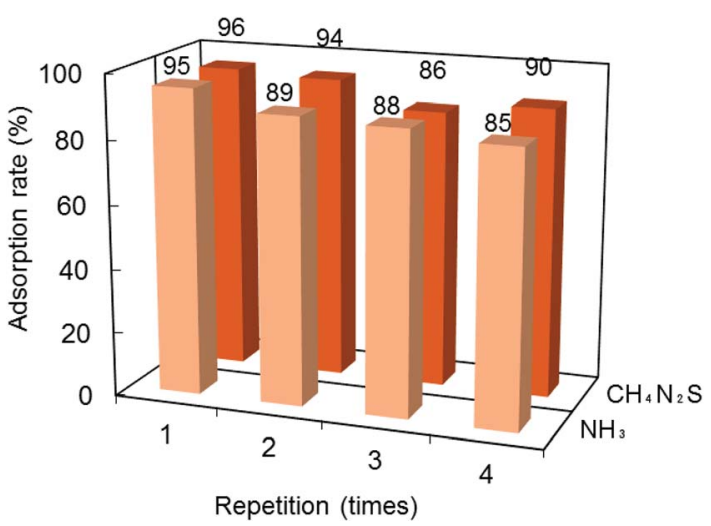

Fig. 6 Evaluation of the adsorption-desorption recycling using the $\mu$-T2 sample after the desorption of palladium(॥) with two different stripping solutions.

\section{Adsorption isotherm of palladium(II)}

To investigate the adsorption mechanism of the Pd(II) ions on the $\mu$-T2 microspheres, we tried to fit the Langmuir adsorption model by evaluating the relationship between the amount of palladium(II) adsorbed on the $\mu$-T2 sample and that remaining in the equilibrium solution. Here, the Langmuir isotherm is expressed by the following eqn (2), which can be used to determine the adsorption capacity and equilibrium constant:

$$
\frac{C_{\mathrm{e}}}{q}=\frac{1}{W_{\mathrm{s}}} C_{\mathrm{e}}+\frac{1}{a W_{\mathrm{s}}}
$$

where $q$ is the amount of palladium(II) adsorbed per gram of microspheres at equilibrium, $C_{\mathrm{e}}$ is the residual metal concentration in the solution after adsorption, $W_{\mathrm{s}}$ is the maximal amount of palladium(II) adsorbed per unit weight of adsorbent and $a$ is the equilibrium constant related to the affinity of the adsorption sites for palladium(II). When plotted as a graph, the equilibrium constant can be estimated by the value of the intercept.

In the adsorption isotherm experiments, $1.0 \mathrm{~mol} \mathrm{dm} \mathrm{dm}^{-3}$ hydrochloric acid was used and the equilibrium $\mathrm{pH}$ after adsorption was kept in the range of 0.01 to 0.07 . As shown in Fig. 7a, the plot of $C_{\mathrm{e}} / q$ vs. $C_{\mathrm{e}}$ had a good linear fit, with an $R^{2}$ value of 0.9989 . From this linear relationship, the value of $W_{\mathrm{s}}$, which is the slope of the straight line, was calculated as 0.136 $\left(\mathrm{mmol} \mathrm{g}^{-1}\right.$ ) (i.e. $14.4 \mathrm{mg} \mathrm{g}^{-1}$ ), while the adsorption equilibrium constant $(a)$ was determined as $48.1\left(\mathrm{mmol} \mathrm{dm}^{-3}\right)^{-1}$. Using the values of $a$ and $W_{\mathrm{s}}$, the adsorption isotherm was drawn and is shown in Fig. 7b. It is clear that the experimental data is in good agreement with the theoretical curve. Emre et al. reported that the adsorption capacity of a melamine-formaldehyde-thiourea resin was $15.3 \mathrm{mg} \mathrm{g}^{-1}\left(0.144 \mathrm{mmol} \mathrm{g}^{-1}\right)$ for palladium(II). ${ }^{24} \mathrm{So}$, it can be said that the adsorption ability of the $\mu$-T2 sample is nearly equal to that of this chelating resin.

\section{Adsorption from a dilute palladium solution}

Since the $\mu$-T2 sample was proven to have a high selectivity for palladium ions, it was expected to be suitable for the adsorption of Pd(II) from a dilute solution. To test the adsorption efficiency of the $\mu$-T2 sample in a dilute solution, experiments were carried out on the adsorption of Pd from low concentrations in the order of ppm to ppb at different adsorption times. As shown in Fig. 8, when the concentrations of Pd(II) ions were 1-10 ppm, an adsorption time of $24 \mathrm{~h}$ was sufficient to allow the recovery of $\operatorname{Pd}($ II) ions at over $95 \%$. As the Pd(II) concentration was decreased to $100 \mathrm{ppb}\left(0.001 \mathrm{mmol} \mathrm{dm}^{-3}\right)$, the adsorption time needed to extended to $48 \mathrm{~h}$ for quantitative recovery. Surprisingly, for a contact time of $48 \mathrm{~h}, 95 \%$ of $\mathrm{Pd}(\mathrm{II})$ was recovered, even though the Pd(II) concentration was lowered to $10 \mathrm{ppb}$ $\left(0.0001 \mathrm{mmol} \mathrm{dm}^{-3}\right)$. This result suggests that the theophyllinebearing microspheres are capable of being used as a very convenient and sensitive material to detect trace amounts of palladium(II) in solution. In recent years, a highly sensitive chemosensor for palladium was reported using complexing agents for the detection of palladium from a dilute solution. ${ }^{25-27}$ Alternatively, there was also a report on the use of potassium 

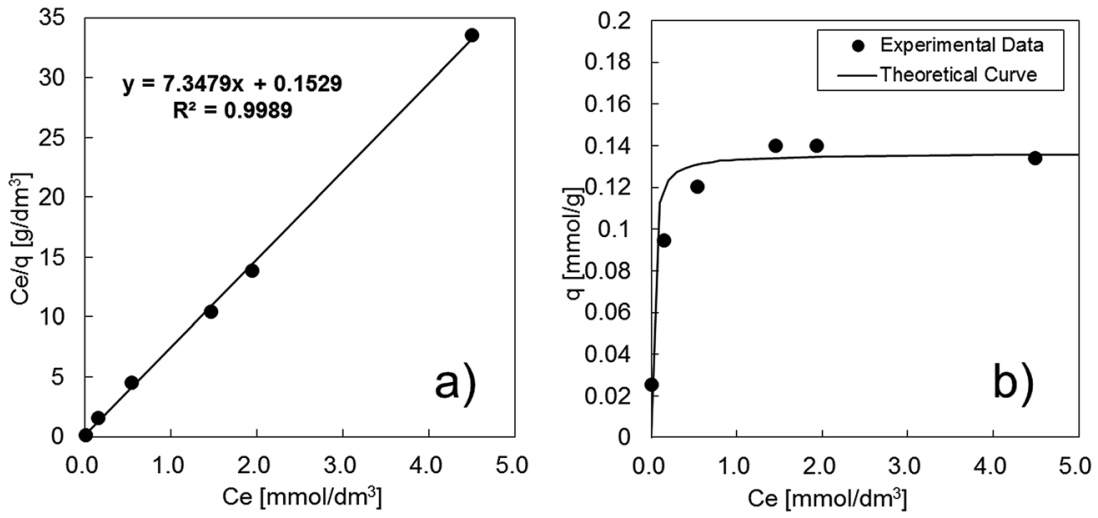

Fig. 7 (a) Langmuir plot of the $\mu-\mathrm{T} 2$ sample based on eqn (2) and (b) a comparison of the adsorption isotherm data and theoretical curve for the $\mu$-T2 sample.

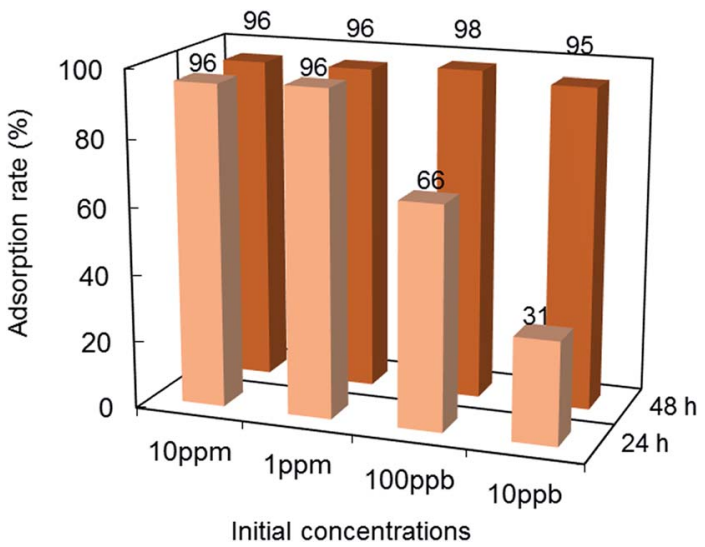

Fig. 8 Adsorption of palladium(॥) from low concentration palladium(॥) solutions using the $\mu$-T2 sample.

isopropyl xanthate as an ultra-efficient palladium scavenger, which was capable of removing residual palladium from active pharmaceutical ingredients to levels of less than 1 ppm. ${ }^{28}$ No doubt, the theophylline-bearing $\mu$-T2 microspheres would be a good candidate for use as a $\operatorname{Pd}($ II) sensor and scavenger.
In order to address its characteristics after palladium adsorption, a powder of the $\mu$-T2 adsorbed palladium ( $\mu$-T2/Pd) microspheres, after being used for $48 \mathrm{~h}$, was subjected to diffusion reflective UV-vis spectroscopic measurements. The absorption spectra of the $\mu-\mathrm{T} 2 / \mathrm{Pd}$ sample obtained from the different concentrations of palladium solutions are shown in Fig. S4. $\dagger$ Similar to a standard sample of a benzyltheophylline$\mathrm{PdCl}_{2}$ complex (BzTh-PdCl${ }_{2}$ ), the $\mu$-T2/Pd sample exhibited an absorption at around $420 \mathrm{~nm}$, indicating the formation of a Pdcomplex on the microspheres after the adsorption of Pd(II) ions.

\section{Catalytic function in a coupling reaction}

There have been a number of reports where polymer-supported palladium nanoparticles have been used as catalysts in carboncarbon coupling reactions. ${ }^{29-32}$ Therefore, it was reasonable to assume that the palladium-adsorbed $\mu$-T2 microspheres could be used as a catalyst for a similar purpose. To evaluate the catalytic ability of the $\mu$-T2/Pd sample, we selected a simple Suzuki-Miyaura coupling reaction between bromobenzene and phenylboronic acid. As shown in Table 1, we compared the catalytic activity of different amounts of Pd-loaded $\mu$-T2 microspheres $(\mu$-T2/Pd) $(0.02,0.2$ and $2.0 \mathrm{~mol} \%-\mathrm{Pd})$, and found

Table 1 Results of the Suzuki-Miyaura cross-coupling reactions in presence of $\mu-\mathrm{T} 2 / \mathrm{Pd}^{a}$
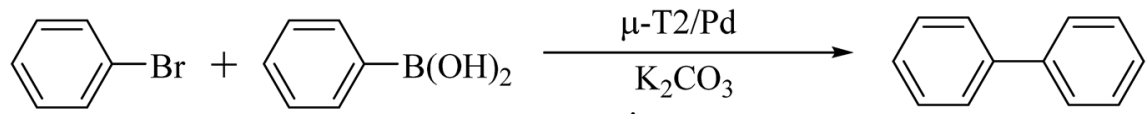

in water

\begin{tabular}{|c|c|c|c|c|c|}
\hline Entry & Solvent & Catalyst & $T /{ }^{\circ} \mathrm{C}$ & Time/h & Yield $^{b}(\%)$ \\
\hline 1 & $\mathrm{H}_{2} \mathrm{O}$ & $0.02 \mathrm{~mol} \%$ & 80 & 1 & 48 \\
\hline 2 & $\mathrm{H}_{2} \mathrm{O}$ & $0.2 \mathrm{~mol} \%$ & 80 & 1 & 71 \\
\hline 4 & $\mathrm{H}_{2} \mathrm{O}$ & $0.02 \mathrm{~mol} \%$ & 50 & 1 & 4 \\
\hline 5 & $\mathrm{H}_{2} \mathrm{O}$ & $0.2 \mathrm{~mol} \%$ & 50 & 1 & 65 \\
\hline 6 & $\mathrm{H}_{2} \mathrm{O}$ & $2.0 \mathrm{~mol} \%$ & 20 & 1 & 100 \\
\hline
\end{tabular}

${ }^{a}$ Reaction condition: bromobenzene ( $\left.1.0 \mathrm{mmol}\right)$, phenylboronic acid $(1.5 \mathrm{mmol}), \mathrm{K}_{2} \mathrm{CO}_{3}(2.5 \mathrm{mmol})$, solvent $(2.0 \mathrm{~mL}){ }^{b}$ Yields were determined by ${ }^{1} \mathrm{H}-\mathrm{NMR}$ analysis. 
that the yield of biphenyl was $100 \%$ using $2.0 \mathrm{~mol} \%-\mathrm{Pd}$, while the yield was lowered to $65 \%$ using $0.2 \mathrm{~mol} \%-\mathrm{Pd}$ under the conditions of an aqueous medium at $50{ }^{\circ} \mathrm{C}$ for $1 \mathrm{~h}$. This result is competitive to the results described in ref. 30 and 31 , where heterogeneous catalytic systems of $\mathrm{Pd}-\mathrm{N}$-heterocyclic carbine were used. In the former study, the yield of biphenyl was $95 \%$ at $50{ }^{\circ} \mathrm{C}$ for $6 \mathrm{~h}$ and in the latter study, the yield of biphenyl was $99 \%$ at $80{ }^{\circ} \mathrm{C}$ for $5 \mathrm{~h}$. Here, the recycling test was also performed in the presence of the $2 \mathrm{~mol} \% \mu$-T2/Pd catalyst and $\mathrm{K}_{2} \mathrm{CO}_{3}$ at $50{ }^{\circ} \mathrm{C}$ for $1 \mathrm{~h}$. Unexpectedly, the yield of biphenyl decreased from 100 to $43 \%$ as the catalyst was used for the 4 th time (Fig. S5 $\dagger$ ). From the SEM observations of the catalyst after the 4 th use, it was revealed that the spherical morphology of the initial microspheres was completely destroyed and there was a large irregular agglomeration of the destroyed particles (Fig. S6 $†$ ). We believe this to be a major reason for the deactivation of the catalyst. The destruction is probably due to the magnetic stirring, in which there was violent rubbing between the microspheres and the stirrer bar. Better stirring to retain the intact morphology of the microspheres was achieved using vibrations in a bioshaker in the reuse of the $\mu$-T2 microspheres in the $\operatorname{Pd}(\mathrm{II})$ desorption and adsorption experiments.

\section{Conclusions}

We have successfully developed an excellent adsorbent material, polystyrenic sub-5 micrometer $\mu$-T2 spheres with a cocontinuous porous structure bearing theophylline residues through the interior and exterior surface. The $\mu$-T2 microspheres showed good water-wettability and swelling properties, and were thus suitable to be used in aqueous media as a hydrophilic absorbent. Thanks to the powerful coordinating ability of the theophylline residues to $\mathrm{Pd}(\mathrm{II})$ ions, the $\mu$-T2 microspheres exhibited excellent adsorption ability towards Pd ions under strong acidic aqueous conditions and could be used repeatedly in adsorption-desorption experiments. In particular, the $\mu$-T2 microspheres were able to detect Pd ions in highly diluted solutions with concentrations of around $10 \mathrm{ppb}$. Such sensitivity is desirable in an integrated Pd sensor. Moreover, the Pd-loaded $\mu$-T2 sample was also able to act as a catalyst to promote a Suzuki-Miyaura $\mathrm{C}-\mathrm{C}$ coupling reaction in an aqueous reaction medium.

\section{Conflicts of interest}

There are no conflicts to declare.

\section{Acknowledgements}

This work was supported in part by the MEXT Supported Program for the Strategic Research Foundation at Private Universities: "Creation of new fusion materials by integration of highly-ordered nano-inorganic materials and ultra-precisely controlled organic polymers" (2013-2017), no. S1311032.

\section{References}

1 Precious Metals Management, Johnson Matthey, https:// www.platinum.matthey.com/, (accessed May 2018).

2 E. Mladenova, I. Karadjova and D. L. Tsalev, J. Sep. Sci., 2012, 35, 1249-1265.

3 M. Sayın, M. Can, M. Imamoglu and M. Arslan, React. Funct. Polym., 2015, 88, 31-38.

4 N. Muslu and M. Gulfen, J. Appl. Polym. Sci., 2011, 120, 33163324.

5 E. Mildan and M. Gulfen, J. Appl. Polym. Sci., 2015, 132, 42533.

6 J. M. Sánchez, M. Hidalgo and V. Salvadó, React. Polym., 2001, 46, 283-291.

7 J.-H. Zu, S.-Q. He, Y. C. Nho, J. J. Pyo and F. Yan, J. Appl. Polym. Sci., 2010, 116, 1414-1421.

8 Z.-H. Yao, L. Rao and J. Xu, J. Appl. Polym. Sci., 2002, 83, 1986-1992.

9 M. Ruiz, A. M. Sastre, M. C. Zikan and E. Guibal, J. Appl. Polym. Sci., 2001, 81, 153-165.

10 S. Morisada, Y.-H. Kim, T. Ogata, Y. Marutani and Y. Nakano, Ind. Eng. Chem. Res., 2011, 50, 1875-1880.

11 D. Nagai, T. Kuribayashi, H. Tanaka, H. Morinaga, H. Uehara and T. Yamanobe, RSC Adv., 2015, 5, 30133-30139.

12 D. Nagai and T. Kimoto, RSC Adv., 2016, 6, 103304-103310.

13 K. Kaikake and Y. Baba, Anal. Sci., 2001, 17, 411-415.

14 K. Kaikake and Y. Baba, Solvent Extr. Ion Exch., 2002, 20(4-5), 491-503.

15 S.-B. Shen, T.-L. Pan, X.-Q. Liu, L. Yuan, Y.-J. Zhang, J.-C. Wang and Z.-C. Guo, J. Colloid Interface Sci., 2010, 345, 12-18.

16 S. Marcel, E. Nov and I. Fisher, J. Polym. Sci., Part A: Polym. Chem., 1991, 29, 347-355.

17 N. Kihara, Y. Adachi, K. Nakao and T. Fukutomi, J. Appl. Polym. Sci., 1998, 69, 1863-1873.

18 D. Soma and R.-H. Jin, RSC Adv., 2017, 7, 36302-36312.

19 R. Guterman, M. Antonietti and J.-Y. Yuan, Macromol. Rapid Commun., 2017, 38, 1600748.

20 K. P. Lok and C. K. Ober, Can. J. Chem., 1985, 63, 209-216.

21 Y.-C. Liang, F. Svec and J. M. J. Frechet, J. Polym. Sci., Part A: Polym. Chem., 1997, 35, 2631-2643.

22 J. A. Bonham, M. A. Faers and J. S. van Duijneveldt, Soft Matter, 2014, 10, 9384-9398.

23 J. Willenbacher, O. Altintas, V. Trouillet, N. Knöfel, M. J. Monteiro, P. W. Roesky and B.-K. Christopher, Polym. Chem., 2015, 6, 4358-4365.

24 E. Birinci, M. Gülfen and A. O. Aydın, Hydrometallurgy, 2009, 95(1-2), 15-21.

25 Y.-S. Zhang, R. Balamurugan, J.-C. Lin, S. Fitriyani, J.-H. Liu and A. Emelyanenko, Analyst, 2017, 142, 1536-1544.

26 L. Cui, W.-P. Zhu, Y.-F. Xu and X.-H. Qian, Anal. Chim. Acta, 2013, 786, 139-145.

27 H. Ren, C. A. Strulson, G. Humphrey, R. Xiang, G. Li, D. R. Gauthiera and K. M. Maloney, Green Chem., 2017, 19, 4002-4006. 
28 Y.-M. Zhou, J.-L. Zhang, H. Zhou, Q.-Y. Zhang, T.-S. Ma and J.-Y. Niu, Sens. Actuators, B, 2012, 171-172, 508-514.

29 E. Mohammadi and B. Movassagh, J. Mol. Catal. A: Chem., 2016, 418-419, 158-167.
30 S.-J. Xu, K.-P. Song, T. Li and B. Tan, J. Mater. Chem. A, 2015, 3, 1272-1278.

31 J.-H. Kim, J.-W. Kim, M. Shokouhimehr and Y.-S. Lee, J. Org. Chem., 2005, 70, 6714-6720.

32 A. Molnar, Chem. Rev., 2011, 111, 2251-2320. 